\title{
Renal amyloidosis
}

\author{
NF JONES
}

From St Thomas's Hospital, Lambeth Palace Road, London SEI

In the study of amyloid and amyloidosis the main interest at present is concerned with our increasing knowledge of the composition and formation of amyloid, and the approaches to treatment that have arisen from this knowledge. This symposium deals with renal disease but it is appropriate to begin with a brief review of our present understanding of the nature of amyloid.

The history of the study of amyloid is studded with illustrious names. Credit for the first description of this substance is usually given to Rokitansky in 1842 . In the early 1850's Virchow was led by the appearance of the tissue deposits of amyloid to suggest that it had a polysaccharide composition. Those who believe that rapidity of communication is a feature of the mid-twentieth century would do well to look at the speed with which some information was disseminated between interested parties in the first half of the nineteenth century, and amyloid provides one such instance. In 1856, within eighteen months of Virchow's main publications on amyloid, Wilks in the Guy's Hospital Reports described a series of 45 cases of the "lardaceous disease." In that same decade, the distinguished chemist Kekule demonstrated the proteinaceous nature of amyloid deposits. A little later Ehrlich described the clinical associations and general pathology of amyloid. In 1924 Domagk, of sulphonamide fame, pointed to the association between amyloid formation and abnormalities in the reticuloendothelial system, while in 1931 MagnusLevy inferred from the occurrence of amyloid in patients with myelomatosis that its formation was in some way connected to the Bence Jones proteins. Apitz in 1940 drew attention to the finding of abnormal numbers or types of plasma cells in the marrow of patients with apparently "primary" amyloid.

The classification of amyloidosis into "primary" and "secondary," introduced by Reiman in 1935," always had to place the amyloidosis which may complicate myelomatosis in a special category. Subsequent attempts at classification of amyloidosis on histological grounds, ${ }^{2}$ or solely on the pattern of organ distribution ${ }^{3}$ also proved unreliable in the delineation of intrinsically coherent groups. Electron microscopy revealed the fibrillary nature of amyloid $\vec{\omega}$ and it was eventually shown that some $90 \%$ or mores of amyloid deposits are made up of characteristico non-branching fibrils, which are approximately $10 \mathrm{~nm} \omega$ in diameter. In parallel with ultrastructural studies of these fibrils, observations were forthcoming, par- $\overrightarrow{-}$ ticularly from Osserman, ${ }^{4}$ which showed that Bence $\vec{N}$ Jones proteins were demonstrable in serum or urine $\infty$ from a large proportion of patients with apparently을 "primary" amyloidosis. This finding acquired new significance with the demonstration that some im- $Z$ munoglobulin light chains could be made by pro-市 teolysis to yield fibrils with the characteristics of those found in amyloid. ${ }^{5}$ Subsequent studies have足 indicated considerable heterogeneity in the composition, and by inference, derivation of amyloid fibriß. Nonetheless, $x$-ray crystallographic and infrared. spectroscopic analyses have revealed that all amylogid fibrils appear to have a "beta-pleated sheet" con-s figuration. ${ }^{6} 7$ This configuration is exceedingly un-o usual in the mammalian world, being better known in invetrebrates.

\section{Amyloid proteins}

It is now known that several different amyloid? proteins may be found as the chief components of the fibrils in different varieties of amyloidosis. All fibrils, however, are believed to have the beta-pleated sheet 3 . arrangement. Adjacent polypeptide chains areo arranged in an antiparallel fashion, that is with the carboxy and amino terminals of adjacent chains ${ }_{\circ}$ being situated at opposite ends. The beta-pleated sheet configuration confers upon amyloid the optical and tinctorial properties that it shows when stained with Congo red. The dye molecules are o aligned in parallel with the axial folds of paired amyloid filaments, and this arrangement underlies the birefringence patterns which are characteristic of ${ }^{\omega}$ amyloid when viewed by polarised light. It is likely? that the beta-pleated sheet configuration is also responsible for the well known insolubility of ${ }_{\mathscr{D}}^{\mathbb{D}}$ amyloid in various physiological solvents, and its resistance to proteolysis, factors that have proved ${ }^{\circ}$ major barriers both to the elucidation of its structure $\frac{\mathbb{D}}{\mathbb{D}}$ 
Table 1 Amyloid fibril proteins and their precursors (related proteins) in different types of amyloidosis

\begin{tabular}{|c|c|c|}
\hline Amyloidosis type & Major fibril protein & Related protein \\
\hline \multicolumn{3}{|l|}{ Acquired systemic } \\
\hline Myeloma & AL & $\mathbf{L}$ \\
\hline Immunocyte dyscrasias & AL & L \\
\hline Reactive (chronic & & \\
\hline \multirow{2}{*}{\multicolumn{3}{|c|}{ Heredofamilial }} \\
\hline & & \\
\hline $\begin{array}{l}\text { eg Portuguese } \\
\text { Non-neuropathic }\end{array}$ & $\mathbf{A F}_{\mathbf{P}}$ & Prealbumin \\
\hline eg FMF & AA & A \\
\hline Localised & & \\
\hline Endocrine thyroid & $\mathrm{AE}_{\mathrm{T}}$ & Calcitonin \\
\hline \multicolumn{3}{|l|}{ Organ-limited } \\
\hline Senile cardiac & $\mathbf{A} \mathbf{S}_{\mathbf{c}}$ & $?$ \\
\hline Cerebral plaques & $?$ & ? \\
\hline
\end{tabular}

$\mathbf{L}=$ light chains.

$\mathbf{A}=$ serum amyloid A protein subunits.

and to its removal from organs in human disease.

To date, the amyloid proteins and their precursors shown in Table 1 have been identified. The AL protein is found to be the main component of amyloid fibrils in multiple myeloma and also in "primary" amyloidosis, a condition which we now recognise as associated usually, and perhaps always, with an abnormality of immunocytes resulting in the production of free light chains. The AL proteins consist of polypeptide chains derived from immunoglobulins; the amino acid sequence of these chains has been shown on a number of occasions to be identical with part of the sequence of circulating light chains from the same patient. Moreover, there is a similar preponderance of lambda light chains in the AL proteins of myeloma-associated amyloid and "primary" amyloid as in the paraproteins and free light chains in the latter two diseases. Enzymatic digestion of Bence Jones proteins in vitro has shown that typical amyloid fibrils with a beta-pleated sheet configuration can be formed from some, but not all, Bence Jones proteins. This may account for the apparent limitation of susceptibility to amyloid deposition to only a relatively small percentage of patients with, for instance, myelomatosis.

Amyloid protein found in "secondary" amyloidosis, associated with chronic inflammatory disease, is not derived from light chains and is designated amyloid AA protein. This protein has been the predominant component of amyloid fibrils isolated from patients with rheumatoid arthritis, and also appears to be the amyloid protein found in patients with Familial Mediterranean Fever. In the search for the precursor of this amyloid protein most attention has been focused on the role of serum amyloid A protein (SAA). This is an acute phase reactant, the concentration of which in serum varies in a very similar manner to that of $\mathrm{C}$-reactive protein. It exists in a high molecular weight form, approximately 180000 daltons, and as such seems to be associated with a lipoprotein. After denaturation a much smaller protein subunit of around 12000 daltons is obtained, and the amino acid sequence of this subunit has been shown to be identical with part of the AA amyloid fibril protein. There is evidence that microheterogeneity exists within the SAA species, thus raising the possibility that only some forms of SAA may be amyloidogenic. This might help to explain the apparent susceptibility of only some individuals with various chronic inflammatory disorders to develop amyloidosis.

Other forms of amyloid protein are now also recognised. The amyloid which occurs in certain endocrine glands is designated AE protein. That found in medullary carcinoma of the thyroid appears to have calcitonin or precalcitonin as its precursor, while the amyloid which occurs in the islets of Langerhans may be derived from insulin. Among the heredofamilial forms of amyloidosis, only the Portuguese neuropathic type has so far been studied in any detail. Here the amyloid fibril protein is designated $A_{P}$ and appears to be chemically related to prealbumin.

Considering this unexpected heterogeneity in the composition of amyloid, Glenner has proposed that, as the unifying factor now seems to be the betapleated sheet configuration, the amyloidoses should be renamed the "beta-fibrilloses." 8

All forms of amyloid contain the so-called P-component. This is a pentagonal subunit with molecular weight of around 24000 daltons. It is identical with a glycoprotein found in normal plasma and referred to as serum amyloid P-component (SAP). This substance again behaves as an acute phase reactant, at least in mice, in which its concentration is increased by treatment with casein in those strains which develop amyloid when so treated. This increase is blocked by pretreatment with colchicine which also prevents the formation of amyloid in this animal. It should be emphasised that considerable variation in the behaviour of SAP occurs between species; for example, its concentration does not increase during an acute phase reaction in man. It has recently been shown that an antibody to SAP reacts with a constituent of normal human glomerular basement membrane and with the vascular basement membranes in some other tissues. ${ }^{9}$ In the human glomerulus this SAP-like material is found in the lamina rara interna (see above Moffat DB page 1197) and it is of interest that this is probably the first site of amyloid formation in the glomerulus in human disease. Abnormalities in the distribution of SAP material in the glomerulus have been identified by immunofluorescent staining techniques 
in various renal diseases, including the "minimal change" lesion. The precise role of SAP in basement membranes in the pathogenesis of amyloidosis remains unknown, but it seems possible that it may prove to be an important factor in determining the localisation of amyloid deposition. Table 2 summarises present views of the factors possibly involved in the pathogenesis of amyloid.

Table 2 Factors possibly involved in the formation of amyloid

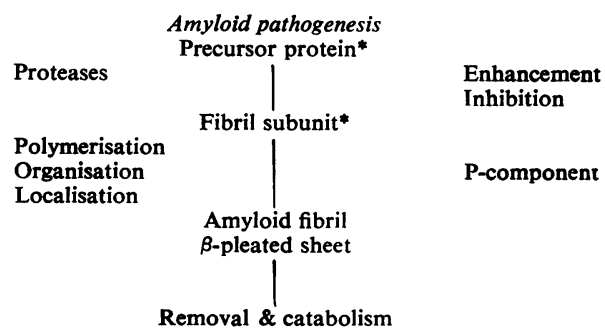

*Individual heterogeneity probable.

\section{Clinical aspects of renal amyloidosis}

Renal amyloidosis is encountered not infrequently in the practice of nephrology, although its incidence has varied from 3 to $12 \%$ in different published renal biopsy series, there being a tendency for its incidence to fall as the size of the series reported increases. Considerable variations are also found in published accounts concerning the relative incidence of the various diseases associated with secondary amyloidosis. These variations probably result chiefly from differences in referral patterns and the special interests of the centres concerned. In the United Kingdom, tuberculosis remains an important cause of secondary amyloidosis, accounting for $24 \%$ of 80 consecutive patients with renal amyloidosis seen at my own hospital, and for $50 \%$ of 40 cases reported from Scotland.10 In two series published from England, "primary" amyloidosis was responsible for approximately $20 \%$ of 98 cases in which the diagnosis of amyloidosis was made by renal biopsy. ${ }^{11} 12$ It is noteworthy that amyloid is often unsuspected when the renal biopsy is performed, usually in the nephrotic syndrome or because of unexplained renal failure. Routine examination for amyloid in renal biopsies is therefore mandatory.

The clinical and biochemical picture produced by amyloid deposition in the kidneys has no unique features. Proteinuria is almost invariable and frequently very heavy, even when the glomerular filtration rate is low. Despite past claims that renal amyloidosis was part of the pattern of organ distribution considered characteristic of the secondary form of this disease, proteinuria was also found in 90 of 115 patients with "primary" amyloidosis reported from the Mayo Clinic. ${ }^{13}$ Usually the proteinuria is poorly selective, but highly selective proteinuria may $\overrightarrow{\overline{\mathrm{N}}}$ be encountered and this may become progressively less selective as the disease progresses. The urinary $\frac{}{0}$ sediment may show protein casts but haematuria, especially when macroscopic, is sufficiently $\mathbb{\nabla}$ uncommon in amyloidosis to justify a careful consideration of alternative causes. Amyloid fibrils ${ }^{\infty}$ have been described in the urinary sediment but this $\vec{\circ}$ has not yet found an accepted place in diagnosis, $\overrightarrow{\vec{\omega}}$ and similar material may be encountered in the urinary sediment from patients who prove not to have amyloid in their kidneys. Although glomerular $\omega$ involvement is usually prominent, with proteinuria and impairment of glomerular filtration as the chief $\overrightarrow{-}$ consequences, isolated defects in tubular function $\vec{N}$ may also occur. Occasionally, the renal medulla is $\mathbb{N}_{\infty}$ the main site for amyloid deposition in the kidneys and, rarely, this may be associated with florid vasopressin-resistance, resulting in nephrogenic $Z$ diabetes insipidus.1415 Renal tubular acidosis, of both distal and proximal varieties, has been described in a few patients. ${ }^{1617} \mathrm{I}$ am unaware of any study which specifically sought to show defects in acidification, and their true incidence remains unknowo.. The most important consequence of amylowi. deposition in the kidneys is renal failure whisid remains a common cause of death in all forms of acquired systemic amyloidosis.

\section{Diagnosis}

In systemic amyloidosis positive biopsies have been obtained from a variety of sites (Table 3 ). Rectal biopsy has been most commonly performed ando

Table 3 Biopsy sites used in the diagnosis of amyloidosis:

\begin{tabular}{|c|c|}
\hline \multicolumn{2}{|l|}{ Amyloid biopsy sites } \\
\hline Rectal & \\
\hline $\begin{array}{l}\text { Renal } \\
\text { Subcutaneous fat }\end{array}$ & $?$ \\
\hline Splenic aspiration & \\
\hline Jejunal & \\
\hline Liver & \\
\hline Skin & \\
\hline Bone marrow & \\
\hline Endomyocardial & \\
\hline
\end{tabular}

here it is essential that the specimen includes the submucosa, and also that the histopathologist iso informed that amyloidosis is suspected so that the appropriate stains are used. In the examination of ${ }^{f}$ tissue for amyloid the most reliable technique is detection of the characteristic birefringence in $\frac{\vec{D}}{\mathrm{D}}$ 
polarised light exhibited by sections stained with Congo red or Sirius red. At present immunofluorescence is of no particular value in the diagnosis but this situation may well change with the possible significance of SAP in the glomerular basement membrane, and its detection by a fluoresceinlabelled antibody. Electron microscopy reveals the characteristic fibrils of amyloid and in early cases this technique is occasionally essential for the diagnosis to be made. It has been claimed that amyloid $\mathbf{A}$ and amyloid $\mathrm{L}$ proteins may be distinguished in histological sections by incubation with potassium permanganate. After this incubation amyloid A protein, as found in "secondary" amyloidosis or in Familial Mediterranean Fever, loses its affinity for Congo red, whereas amyloid L protein does not. This technique has, however, given rather variable results in the hands of different histopathologists.

\section{Treatment}

The poor prognosis in amyloidosis and the importance of renal failure as a cause of death has compelled an interest in the treatment of this condition for the nephrologist. ${ }^{18}$ Growing awareness of the similarities between "primary" amyloidosis and that associated with myelomatosis led to the trial of cytotoxic drugs such as melphalan in the former condition. ${ }^{19} 20$ Published reports contain a number of anecdotes in which apparently impressive and unexpected improvements followed the use of melphalan, or melphalan combined with steroids or with steroids and fluoxymesterone; 2122 the course in other patients, however, does not seem to have been affected. Controlled trials are difficult to arrange because of the rarity of this condition, but are now underway and preliminary reports are not encouraging. Moreover, immunosuppression can enhance amyloid formation in some animals. Colchicine has also been used. This drug can prevent amyloid formation in mice (with injections of casein) and it also reduces the frequency and severity of febrile attacks in Familial Mediterranean Fever, a condition commonly complicated by amyloidosis. ${ }^{23}$ The place of this drug cannot yet be properly assessed in the management of human amyloidosis. Dimethylsulphoxide has the ability to dissolve amyloid fibrils in vitro and also reduces the incidence of casein-induced amyloid formation in mice. Some authors have reported that the use of this drug results in increased urinary excretion of an amyloid-like substance both in mice and man, but others have failed to confirm this. Claims have been made for clinical improvement in amyloidosis after treatment with dimethylsulphoxide. ${ }^{24} 25$ One possible factor in some patients may be the anti-inflammatory effect induced by this drug in-for example, rheumatoid arthritis. Its use produces a most unpleasant odour on the breath of some patients. In one series this side effect was so distasteful that it led to the refusal of treatment in eight of 17 patients. ${ }^{24}$ Nevertheless, in this otherwise fatal condition this agent certainly needs further evaluation.

One problem in the interpretation of the apparent results of treatment in uncontrolled trials is the spontaneous fluctuations in proteinuria and in oedema that may occur in patients with renal amyloidosis. Complete remissions have been described in the nephrotic syndrome associated with renal amyloidosis. ${ }^{26} 27$ The inclusion of histological evidence is therefore most important for the proper evaluation of any therapeutic agent claimed to confer benefit in amyloidosis.

Despite these approaches to treatment, death in uraemia remains a common outcome in renal amyloidosis. The suitability of regular dialysis or renal transplantation for patients with amyloidosis therefore arises. Results in Europe reported to the European Dialysis and Transplant Association show that the survival rates for patients with renal amyloidosis receiving regular haemodialysis are less good than for the pooled results of all patients with renal failure so treated. The survival over the first two years of regular haemodialysis in amyloidosis is roughly comparable to that in renal failure caused by diabetes. Difficulties with shunts and fistulae for vascular access do not in general seem to be more frequent in patients with amyloid. More than 100 kidney transplants have been performed in patients whose primary disease was amyloidosis. The development of amyloid in the renal graft has been recorded but was not the cause of graft failure or death in those patients. The information at present available does not seem to justify the denial of maintenance dialysis therapy or of a kidney transplant to a patient solely because renal failure is caused by amyloidosis.

In conclusion, the last decade has seen important advances in our understanding of the nature of amyloid. This gives hope that such knowledge will find increasing therapeutic application in the next decade.

\section{References}

${ }^{1}$ Reiman HA. Recovery from amyloidosis. JAMA 1935;104: 1070-1.

${ }^{2}$ Missmahl HP. Reticulin and collagen as important factors for the localisation of amyloid. In: Mandema E, Ruinen L, Scholten L, Cohen AS, eds. Symposium on Amyloidosis. Amsterdam: Excerpta Medica, 1968:22.

${ }^{3}$ Isobe T, Osserman EF. Patterns of amyloidosis and their association with plasma-cell dyscrasia, monoclonal 
immunoglobulins and Bence Jones proteins. $N$ Engl $J$ Med 1974;290:473-7.

${ }^{4}$ Osserman EF, Takasuki K, Talal N. The pathogenesis of "amyloidosis." Semin Hematol 1964;1 :3-85.

${ }^{5}$ Glenner GG, Terry W, Harada M, Isersky C, Page D. Amyloid fibril proteins. Science 1971;171:1150-1.

${ }^{6}$ Eanes ED, Glenner GG. $X$-ray diffraction studies on amyloid filaments. $J$ Histochem Cytochem 1968;16:673-7.

${ }^{7}$ Termine JD, Eanes ED, Ein D, Glenner GG. Infrared spectroscopy of human amyloid fibrils and immunoglobulin protein. Biopolymers 1972;11:1103-13.

${ }^{8}$ Glenner GG. Amyloid deposits and amyloidosis. The B-fibrilloses. $N$ Engl J Med 1980;302:1283-92.

- Dyck RF, Lockwood CM, Turner D, Evans DS, Rees AS, Pepys MB. Amyloid P-Component in human glomerular basement membrane. Lancet 1980;ii:606-9.

${ }^{10}$ Kennedy AC, Burton JA, Allison MEM. Tuberculosis as a continuing cause of renal amyloidosis. $\mathrm{Br}$ Med J 1974 ;iii : 795-7.

11 Triger DR, Joekes AM. Renal amyloidosis-a fourteen year follow-up. $Q J \mathrm{Med} 1973 ; 42: 15-40$.

12 Jones NF. Renal amyloid. In: Ledingham JGG ed. Advanced Medicine. London: Pitman Medical, 1974:351.

${ }^{13}$ Kyle RA, Bayrd ED. Amyloidosis: review of 236 cases. Medicine (Baltimore) 1975;54:271-99.

${ }^{14}$ Carone FA, Epstein FH. Nephrogenic diabetes insipidus caused by amyloid disease. Am J Med 1960;29:539-44.

${ }^{15}$ Dorhout-Mees EJ, De Planque BA, Helders J, Jooiker CJ. Renal amyloidosis presenting as water-losing syndrome. Nephron 1968;5:81-3.

${ }^{16}$ Sebastian A, McSherry E, Ueki I, Morris RC. Renal amyloidosis, nephrotic syndrome and impaired renal tubular reabsorption of bicarbonate. Ann Intern Med $1968 ; 69: 541-8$.

${ }^{17}$ Luke RG, Allison MEM, Davidson JF, Duguid WP. Hyperkalaemia and renal tubular acidosis due to renal amyloidosis. Ann Intern Med 1969;70:1211-7.
18 Jones NF. Renal amyloidosis-pathogenesis and management. Clin Nephrol 1976;6:459-64.

${ }^{19}$ Barth WF, Willerson JT, Waldmann TA, Decker JL. Primary amyloidosis. Am J Med 1969;47:259-73.

${ }^{20}$ Jones NF, Hilton PJ, Tighe JR, Hobbs JR. Treatment of "primary" renal amyloidosis with melphalan. Lancet 1972;ii:616-9.

21 Cohen JJ, Lessin LS, Hallal J, Burkholder P. Resolution of primary amyloidosis during chemotherapy. Ann Intern Med 1975;82:466-73.

${ }^{22}$ Bradstock K, Clancy R, Uther J, Basten A, Richards J. The successful treatment of primary amyloidosis with intermittent chemotherapy. Aust $N Z J$ Med 1978;8:1769.

${ }^{23}$ Zemer D, Pras M, Shemer Y, Sohar E, Gafui J. Daily prophylactic colchicine in Familial Mediterranean Fever. In: Glenner GG, Pinho Costa P, de Freitas AF, eds. Amyloid and amyloidosis. Amsterdam: Excerpta Medica, $1980 ; 580$.

${ }^{24}$ Osserman EF, Sherman WH, Kyle RA. Further studies of therapy of amyloidosis with dimethylsulfoxide (DMSO). In: Glenner GG, Pinho Costa P, de Freitas AF, eds. Amyloid and amyloidosis. Amsterdam: Excerpta Medica, 1980:563.

${ }^{25}$ Van Rijswijk MH, Ruinen L, Donker AJM, etal. Successful treatment with dimethylsulfoxide of human amyloidosis secondary to rheumatoid arthritis. In: Glenner GG, Pinho Costa P, de Freitas AF, eds. Amyloid and amyloidosis. Amsterdam: Excerpta Medica, 1980:570.

${ }^{26}$ Mery JP, Mostefa S. Remission in renal amyloidosis. Ann Intern Med 1975;83:581.

27 Michael J, Jones NF. Spontaneous remissions of nephrotic syndrome in renal amyloidosis. $\mathrm{Br}$ Med J 1978 ;ii:1592.

Requests for reprints to: Dr NF Jones, St Thomas Hospital, London SE1, England. 